\title{
Complementary effect of fat grafting on traditional subciliary incisional lower blepharoplasty: estimated by the change of lid-cheek junction
}

\author{
Kyoungjin Kang, MD, PhD', Choongyee Chai, $\mathrm{MS}^{2}$ \\ ${ }^{1}$ Seoul Cosmetic Surgery Clinic, Busan, Rep. of Korea, ${ }^{2}$ Korean College of Cosmetic Surgery, Busan, Rep. of Korea
}

\begin{abstract}
Background: Traditional subciliary incision lower blepharoplasty (TSILB) is commonly used for improving aged lower eyelid. Fat grafting has been popularly performed to correct shortcomings of TSILB such as infraorbital hollowness and incomplete blending of lid-cheek junction (LCJ). LCJ has been known as an objective index to measure the aging of lower eyelid. However, there was no study on the changes of LCJ length and shape with complementary fat grafting.

Objective: This study aimed to evaluate the effect of complementary fat grafting by observing the changes in length and shape of the LCJ.

Methods: Between 2010 and 2016, the authors observed the change of LCJ in 33 patients who were followed-up for more than 3 months among patients who underwent TSILB alone (Group 1, G1) or TSILB combined with fat grafting (Group 2, G2). The fat graft was performed by sequential autologous fat injection method, having the concept of volumetric face lifting. The groups were further divided into subgroups G1p, G1n, G2p, and G2n according to positive (p) or negative (n) globe-to-skeletal rim relations. Suborbicularis oculi fat lifting and lateral retinacular canthopexy were mainly performed in patients who had negative vector.

Results: The length of LCJ in G2 decreased significantly compared to that of G1. There was no significant difference between G1p and G1n, and G2p and G2n. The shape of LCJ changed diversely from V-shape to flat shape and was more dramatic in G2 than in G1. In G1, superolateral shifting in lateral points of LCJ was a typical change, but in G2, superolateral shifting and vertical shifting of LCJ were more prominently occurred at medial and middle points of $L C J$, which were mainly induced by fat grafting.

Conclusion: Complementary fat grafting showed better rejuvenation effect through further changes of LCJ in length (shortening) and shape (flattening) than that of TSILB alone.

Level of Evidence: IV
\end{abstract}

Keywords: fat grafting; lid-cheek junction; lower blepharoplasty; subciliary

\section{Introduction}

Lower eyelid aging is characterized by skin laxity, wrinkles, orbital fat protrusion, tear trough deformity, palpebromalar groove, hyperpigmentation, lid laxity, etc. [1].

Tear trough deformity and palpebromalar groove appear at the lid-cheek junction (LCJ), which is a surface landmark of the boundary of the lower eyelids and midface and implies the anatomical and functional relationship of these adjacent zones [2,3]. Aging in this zone occurs simultaneously and dynamically due to volume decrease, laxity, sagging, and bone resorption, which eventually caused the LCJ length to increase.

Received January 23, 2018; Revised March 25, 2018; Accepted March 282018 
Traditional subciliary incision lower blepharoplasty (TSILB), which is a widely used procedure to improve aging of the lower eyelid, showed significant improvement in laxity, protrusion, and sagging, and significantly reduced the LCJ length, but did not show any significant improvement in volume decrease, like infraorbital hollowness [3].

To achieve a more perfect improvement of the aged lower lid, combining TSILB with other volume restoration surgeries, such as fat reposition, fat grafting, and filler injection, has been popularly performed [4-6]. Among these, fat grafting is considered ideal and reliable because it maintains the original anatomical structures and uses autologous tissue. The purpose of the Coleman's [7] method is only for improving volume defect in the tear trough deformities by injecting the fat into subdermal and submuscular plane [8]. However, Kang $[9,10]$ reported that fat graft into the whole layer of the tear trough deformities, palpebromalar grooves, malar eminence, and mid-cheek furrow, eventually, achieved volume restoration and increased skeletal support for the lower lid soft tissue through anterior projection of the zygomaticomaxillary bone.

This study aimed to evaluate the effect of complementary fat grafting by observing the changes in length and shape of the LCJ from TSILB alone and TSILB combined with fat grafting.

\section{Materials and methods}

\section{Patient group}

Between 2010 and 2016, 33 patients (66 sides), who underwent TSILB alone (Group 1, G1) or TSILB combined with fat grafting (Group 2, G2), followed up for more than 3 months were the subjects of this study. Patients were divided into 2 groups of different operations, and each group was subdivided into G1p, G1n, G2p, and G2n according to positive (p) or negative (n) globe-to-skeletal rim relations. If the position of cheek prominence lied anterior to the cornea, it was classified as a positive vector. Moreover, if it lied posterior to the cornea, it was classified as a negative vector [11].

\section{TSILB}

All procedures of TSILB were performed under local anesthesia using a mixture of lidocaine (2\%) and epinephrine (1:100,000). Skin incision was made 2 to $3 \mathrm{~mm}$ from the eyelash of the lower lid. The skin-muscle flap was performed using a radiofrequency module called Timedsurgery ${ }^{\circledR}$ (TIMED TD50 Micropulse; Korpo S.R.l, Genova, Italy). The central and medial orbital fat excluding lateral fat was removed, and then the mar- gin of the septum was sutured using 6-0 polydioxanone monofilament for prevention of recurrent fat protrusion.

In G1n, G2n, and G2p patients with negative vector, suborbicularis oculi fat (SOOF) lifting and/or lateral retinacular canthopexy was performed [3]. For the SOOF lifting, orbital retaining ligament including SOOF was resuspended superolaterally to the periosteum of the lateral orbital rim with threepoint quilting sutures using 5-0 polydioxanone monofilament. In order to do lateral retinacular canthopexy, a double-armed 4-0 prolene was used to suture the lateral retinaculum to the periosteum of the lateral orbital rim. The muscle and skin flaps were redrapped superolaterally after excision of the lax skin and muscle, and the incisions were repaired by suturing with 6-0 polydioxanone monofilament and 6-0 nylon separately.

Postoperatively, a 1/2-inch 3M Micropore ${ }^{\mathrm{TM}}$ surgical tape tan (Scotch; 3M Korea Co. Ltd., Seoul, Korea) was placed on the lower eyelid to support the lid and reduce swelling and further bleeding. Cold compression was applied for 48 hours.

\section{Fat grafting}

The fat grafting was performed just before the skin closure of TSILB. The fat was harvested from the abdomen (or thigh) using a standard suction cannula $(3.0 \mathrm{~mm} \times 25.0 \mathrm{~cm})$ and Luer Lock disposable syringe $(10.0 \mathrm{ml})$ under local tumescent anesthesia and, then, centrifuged at 3,000 rpm for 3 minutes. After centrifugation, the supranatant oil fraction and infranatant tumescent solution were eliminated. The separated fat was recharged to a 1.0-ml disposable syringe, and then Coleman's cannula type II $(18 \mathrm{G} \times 7.0 \mathrm{~cm})$ was attached. Sensory nerve block for the infraorbital and zygomaticofacial nerves and local anesthesia for entry sites were performed using with a $1 \%$ lidocaine with epinephrine $(1: 100,000)$ mixture. The fat was sequentially injected as shown in Fig. 1 using the baton grip technique [11]. In each area, the fat was sequentially injected from the deep to superficial layer as shown in Fig. 1.

\section{Measurement of shape change}

From the pre- and postoperative photographs of the patient, LCJs were identified at six distinct points. The complete shape of the LCJ was determined by connecting each of them, as shown in Fig. 2 [3]. The angle of bcd/ijk was measured using a protractor.

\section{Statistics processing method}

The length of the LCJ was measured at the vertical line of the center of the pupil at $\mathrm{c}(\mathrm{j})$ as shown in Fig. 2 using a desk ruler. 

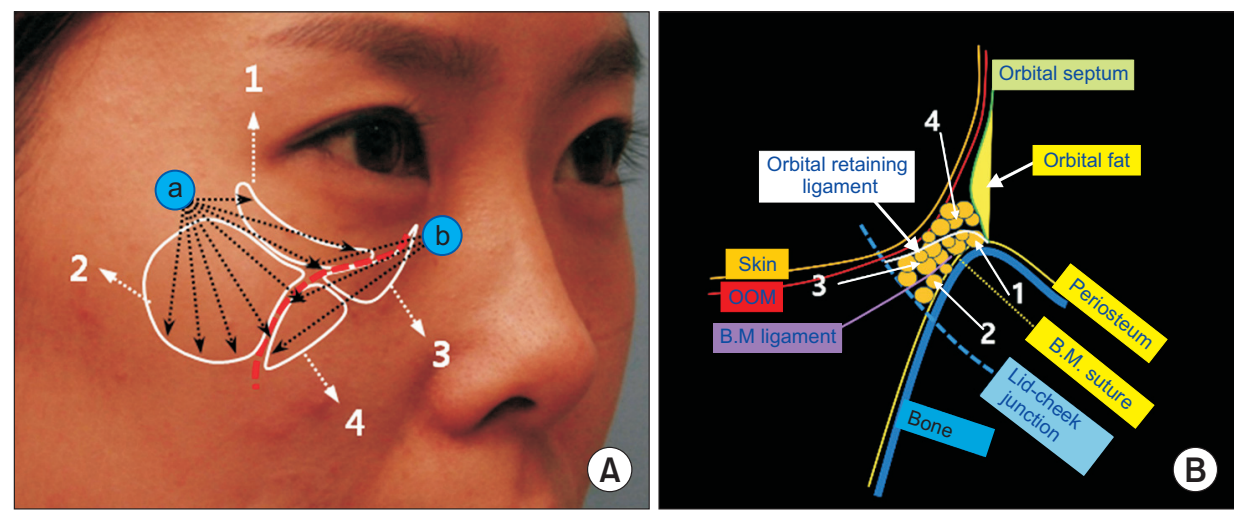

Fig. 1. (A) Method of complement fat grafting. Sequential autologous fat injection for correction of infraorbital hollowness and skeletal supporting of the lower lid. Area 1, palpebromalar groove; area 2, malar area; area 3, tear trough deformity; and area 4, mid-cheek furrow. A red dashed line indicates zygomaticomaxillary suture line. (a) and (b) means entry sites for fat injection and black dotted arrows means the direction of injection. (B) A schimatic drawing for placement and fat injection in order. The numbers $(1,2,3$, and 4$)$ mean fat injection in order. 1, the placement between supraperiosteal layer and orbital retaining ligament; 2 , the placement between supraperiosteal layer and buccomaxillary (B.M.) ligament; 3, placement between two ligaments; 4, placement between orbicularis oculi muscle (OOM) and Orbital retaining ligament.

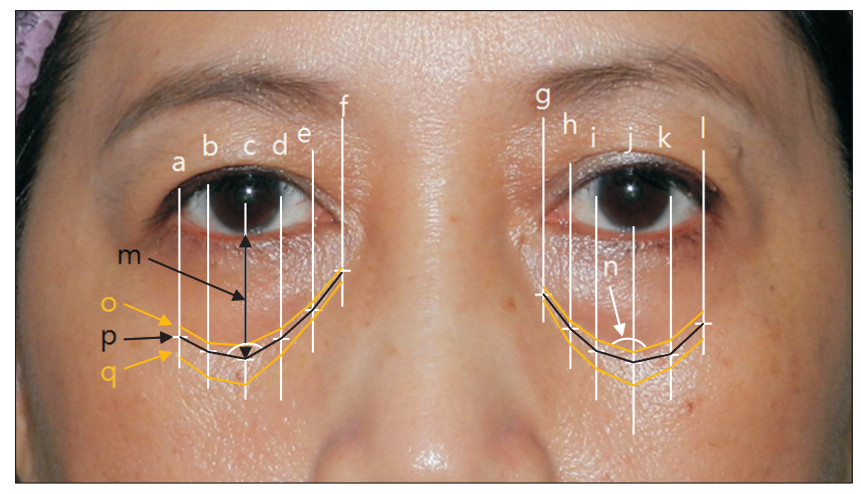

Fig. 2. Lid/cheek junctions and bcd/ijk angle. a(l), line drawn vertically from lateral canthus; $b(k)$, line drawn vertically from lateral limbus; $c(j)$, line drawn vertically from center of pupil; d(i), line drawn vertically from medial limbus; $\mathrm{e}(\mathrm{h})$, the middle line in between $\mathrm{d}(\mathrm{i})$ and $\mathrm{f}(\mathrm{g})$; $\mathrm{f}(\mathrm{g})$, line drawn vertically from medial canthus. m, length of lid/cheek junction at the point of $\mathrm{c}(\mathrm{j}) ; \mathrm{n}, \mathrm{bcd} /$ ijk angle. Three visible lines observed between lower lid and midcheek. o, indicates lower margin of protruded orbital fat; $p$, indicates actual lid cheek junction; and q, indicates demarcation line formed by mid-cheek sagging.

The mean and standard deviation of each group were calculated, in the 95\% confidence interval; paired t-test was used to carry out the pre- and postoperative comparison within the group and subgroup. Analysis of covariance (ANCOVA) test was used to compare the difference of LCJ between the group and subgroups.

\section{Results}

\section{Statistical analysis}

Changes in LCJ length between groups are shown in Table 1. There was no significant age differences between 34 patients of G1 (56.3 \pm 5.32$)$ and 32 patients of G2 (56.6 \pm 6.81$)$. The follow-up period ranged from 3 to 11 months (4.17 \pm 2.09 ).

A statistical analysis of the changes of LCJ from each group and subgroup according to the vector was performed, and results are shown in Table 2. The length of LCJ decreased after surgery in both G1 and G2 irrelevant to the vector, and that of G2 significantly decreased more than that of G1 (ANCOVA test $=15.590, p<0.001)$. Moreover, there was no significant difference in the pre- and postoperative length between each subgroup. However, both G2p and G2n had a significant decrease compared to Glp.

\section{Morphological analysis}

Characteristic morphological changes observed from one clinical case by random sampling from each group are as follows.

\section{Group 1 positive}

Typical pattern of rejuvenation was seen in the left eyelid. The whole length of the LCJ significantly decreased due to the shift of the LCJ in the superolateral direction and the increased ijk angle. In the right eyelid, lid laxity and ectropion were more advanced than the left eyelid preoperatively (Fig. 3A, B). The difference in pre- and postoperative length of LCJ at the middle 
Table 1. Measurements of lid-cheek junction after TSILB and TSILB with fat grafting

\begin{tabular}{|c|c|c|c|c|c|c|c|c|}
\hline \multirow{3}{*}{$\begin{array}{l}\text { No. } \\
\text { of case }\end{array}$} & \multirow{3}{*}{$\begin{array}{l}\text { Age (yr)/ } \\
\text { Sex }\end{array}$} & \multirow{3}{*}{$\begin{array}{l}\text { Follow up period } \\
\text { (mo) }\end{array}$} & \multicolumn{4}{|c|}{ Length of LCJ (mm) } & \multirow{2}{*}{\multicolumn{2}{|c|}{$\begin{array}{l}\text { G-to-S } \\
\text { relationship }\end{array}$}} \\
\hline & & & \multicolumn{2}{|c|}{ Preoperative } & \multicolumn{2}{|c|}{ Postoperative } & & \\
\hline & & & Rt. & Lt. & Rt. & Lt. & Rt. & Lt. \\
\hline \multicolumn{9}{|c|}{ Group 1: TSILB (n=34) } \\
\hline 1 & $47 / \mathrm{F}$ & 3 & 18 & 16.5 & 14 & 14 & $\mathrm{P}$ & $\mathrm{P}$ \\
\hline 2 & $53 / \mathrm{F}$ & 3 & 16.5 & 14 & 14.5 & 17 & $\mathrm{P}$ & $\mathrm{P}$ \\
\hline 3 & $53 / \mathrm{F}$ & 3 & 15 & 17.7 & 14.6 & 15 & $\mathrm{P}$ & $\mathrm{P}$ \\
\hline 4 & $53 / \mathrm{F}$ & 3 & 12 & 13 & 12 & 12 & $\mathrm{P}$ & $\mathrm{P}$ \\
\hline 5 & $60 / \mathrm{F}$ & 3 & 18.9 & 18.5 & 15 & 15.5 & $\mathrm{P}$ & $\mathrm{P}$ \\
\hline 6 & $55 / \mathrm{M}$ & 3 & 19.3 & 18.3 & 17.4 & 17 & $\mathrm{P}$ & $\mathrm{P}$ \\
\hline 7 & $54 / \mathrm{F}$ & 8 & 14.5 & 15 & 12.5 & 12 & $\mathrm{P}$ & $\mathrm{P}$ \\
\hline 8 & $62 / \mathrm{F}$ & 6 & 17 & 16.5 & 15 & 14 & $\mathrm{P}$ & $\mathrm{P}$ \\
\hline 9 & $69 / \mathrm{F}$ & 11 & 17 & 17.7 & 16.7 & 15.5 & $\mathrm{P}$ & $\mathrm{P}$ \\
\hline 10 & $57 / \mathrm{F}$ & 7 & 17 & 14 & 16 & 13.5 & $\mathrm{P}$ & $\mathrm{P}$ \\
\hline 11 & $55 / \mathrm{F}$ & 3 & 20 & 18 & 17.3 & 18 & $\mathrm{P}$ & $\mathrm{P}$ \\
\hline 12 & $53 / \mathrm{M}$ & 3 & 16.5 & 15.5 & 13 & 13.5 & $\mathrm{P}$ & $\mathrm{P}$ \\
\hline 13 & $61 / \mathrm{F}$ & 6 & 18.5 & 18.5 & 16.5 & 15.8 & $\mathrm{P}$ & $\mathrm{P}$ \\
\hline 14 & $52 / \mathrm{F}$ & 7 & 20 & 19.5 & 17.2 & 16.5 & $\mathrm{~N}$ & $\mathrm{~N}$ \\
\hline 15 & $55 / \mathrm{F}$ & 3 & 17.3 & 17 & 13.5 & 15 & $\mathrm{~N}$ & $\mathrm{~N}$ \\
\hline 16 & $58 / \mathrm{F}$ & 3 & 16.5 & 18 & 15.5 & 17 & $\mathrm{~N}$ & $\mathrm{~N}$ \\
\hline 17 & $48 / \mathrm{F}$ & 3 & 17.8 & 18 & 16.1 & 17.1 & $\mathrm{~N}$ & $\mathrm{~N}$ \\
\hline Mean & 56.3 & 4.56 & \multicolumn{2}{|c|}{16.99} & \multicolumn{2}{|c|}{15.15} & & \\
\hline SD & 5.32 & 2.45 & \multicolumn{2}{|c|}{1.94} & \multicolumn{2}{|c|}{1.73} & & \\
\hline \multicolumn{9}{|c|}{ Group 2 : TSILB with fat grafting $(\mathrm{n}=32)$} \\
\hline 1 & $62 / \mathrm{F}$ & 6 & 20.5 & 20 & 17.5 & 19 & $\mathrm{p}$ & $\mathrm{p}$ \\
\hline 2 & $58 / \mathrm{F}$ & 3 & 15 & 15 & 13 & 12.5 & $\mathrm{p}$ & $\mathrm{p}$ \\
\hline 3 & $60 / \mathrm{F}$ & 8 & 15 & 15 & 13 & 13 & $\mathrm{p}$ & $\mathrm{p}$ \\
\hline 4 & $60 / \mathrm{F}$ & 3 & 16 & 17 & 13.5 & 14.5 & $\mathrm{p}$ & $\mathrm{p}$ \\
\hline 5 & $50 / \mathrm{F}$ & 3 & 15.5 & 17 & 13.5 & 13 & $\mathrm{p}$ & $\mathrm{p}$ \\
\hline 6 & $54 / \mathrm{F}$ & 3 & 12.5 & 13 & 12 & 10 & $\mathrm{P}$ & $\mathrm{P}$ \\
\hline 7 & $62 / \mathrm{F}$ & 3 & 16.5 & 15 & 11.5 & 13.5 & $\mathrm{P}$ & $\mathrm{P}$ \\
\hline 8 & $53 / \mathrm{F}$ & 3 & 16 & 14 & 13 & 12.5 & $\mathrm{P}$ & $\mathrm{P}$ \\
\hline 9 & $61 / F$ & 3 & 17 & 16 & 15 & 14 & $\mathrm{P}$ & $\mathrm{P}$ \\
\hline 10 & $62 / F$ & 3 & 19 & 17.1 & 13.9 & 13.7 & $\mathrm{P}$ & $\mathrm{P}$ \\
\hline 11 & $73 / \mathrm{M}$ & 3 & 18.5 & 17.5 & 15.5 & 15.5 & $\mathrm{P}$ & $\mathrm{P}$ \\
\hline 12 & $50 / \mathrm{F}$ & 6 & 18.5 & 19.5 & 13.5 & 14 & $\mathrm{P}$ & $\mathrm{P}$ \\
\hline 13 & $50 / \mathrm{F}$ & 4 & 16.5 & 17 & 13.5 & 14 & $\mathrm{~N}$ & $\mathrm{~N}$ \\
\hline 14 & $48 / \mathrm{F}$ & 3 & 15 & 14.5 & 12.5 & 13 & $\mathrm{~N}$ & $\mathrm{~N}$ \\
\hline 15 & $49 / \mathrm{F}$ & 3 & 18.5 & 17 & 13.5 & 12 & $\mathrm{~N}$ & $\mathrm{~N}$ \\
\hline 16 & $53 / \mathrm{F}$ & 3 & 16.5 & 20.5 & 15.5 & 16 & $\mathrm{~N}$ & $\mathrm{~N}$ \\
\hline Mean & 56.6 & 4.00 & & & & & & \\
\hline SD & 6.81 & 1.53 & & & & & & \\
\hline
\end{tabular}

Values are presented as only number.

TSILB, traditional subciliary incision lower blepharoplasty; LCJ, lid-cheek junction; Rt., right; Lt., left; G-to-S, globe-to-skeletal rim relations; F, female; $\mathrm{M}$, male; $\mathrm{P}$, positive; $\mathrm{N}$, negative.

and lateral part of the eyelid was larger than that of the medial part (Fig. 3C, D). Compared to the left eyelid, less difference in the length of the LCJ was observed. Particularly, the "e" portion in the length of the LCJ decreased more, and the "a" and "b" portions of the LCJ were not much improved; it was mainly due to the flat and small zygomaticomaxillary bone of the right lower orbital rim (2 black arrows) (Fig. 3C, D). Particularly, a decreased bcd angle was considered to be caused by the com- 
Table 2. Changes of the length of lid-cheek junction after TSILB (Group 1) and TSILB with fat grafting (Group 2)

\begin{tabular}{|c|c|c|c|c|c|c|c|c|c|c|}
\hline \multirow[t]{2}{*}{ Group } & \multirow[t]{2}{*}{$\begin{array}{l}\text { G-to-S } \\
\text { (vector) }\end{array}$} & \multirow[t]{2}{*}{$\begin{array}{l}\text { No. of } \\
\text { case }\end{array}$} & \multirow[t]{2}{*}{$\begin{array}{l}\text { Preoperative } \\
(\mathrm{mm})\end{array}$} & \multirow[t]{2}{*}{$\begin{array}{l}\text { Postoperative } \\
(\mathrm{mm})\end{array}$} & \multirow{2}{*}{$\begin{array}{l}\text { Pre-post } \\
\text { difference }{ }^{\text {a) }} \\
\quad(\mathrm{mm})\end{array}$} & \multirow[t]{2}{*}{ t } & \multicolumn{2}{|c|}{$\begin{array}{l}\text { Differences between } \\
\text { positive and negative } \\
\text { vector in each group }^{\text {b) }}\end{array}$} & \multicolumn{2}{|c|}{$\begin{array}{l}\text { Differneces between } \\
\text { Group } 1 \text { and Group } 2^{\text {b) }}\end{array}$} \\
\hline & & & & & & & F & p-value & F & p-value \\
\hline 1 & & 34 & $16.99 \pm 1.94$ & $15.15 \pm 1.73$ & $-1.83 \pm 1.40$ & 7.655 & - & - & 15.590 & $<0.001$ \\
\hline $1 p$ & Positive & 26 & $16.67 \pm 2.03$ & $14.90 \pm 1.79$ & $-1.77 \pm 1.49$ & 6.055 & 0.235 & 0.631 & & \\
\hline $\ln$ & Negative & 8 & $18.01 \pm 1.20$ & $15.99 \pm 1.28$ & $-2.03 \pm 1.08$ & 5.300 & & & & \\
\hline 2 & & 32 & $16.61 \pm 2.03$ & $13.75 \pm 1.72$ & $-2.86 \pm 1.37$ & 11.781 & - & - & & \\
\hline $2 p$ & Positive & 26 & $16.50 \pm 2.10$ & $13.75 \pm 1.85$ & $-2.75 \pm 1.33$ & 10.113 & 0.333 & 0.568 & & \\
\hline $2 n$ & Negative & 8 & $16.94 \pm 1.90$ & $13.75 \pm 1.39$ & $-2.33 \pm 1.47$ & 5.878 & & & & \\
\hline
\end{tabular}

Values are presented as mean \pm SD.

TSILB, traditional subciliary incision lower blepharoplasty; G-to-S, globe-to-skeletal rim relations; p, positive; n, negative.

${ }^{\text {a) }}$ Paired t-test, ${ }^{\text {b) }}$ analysis of covariance test.
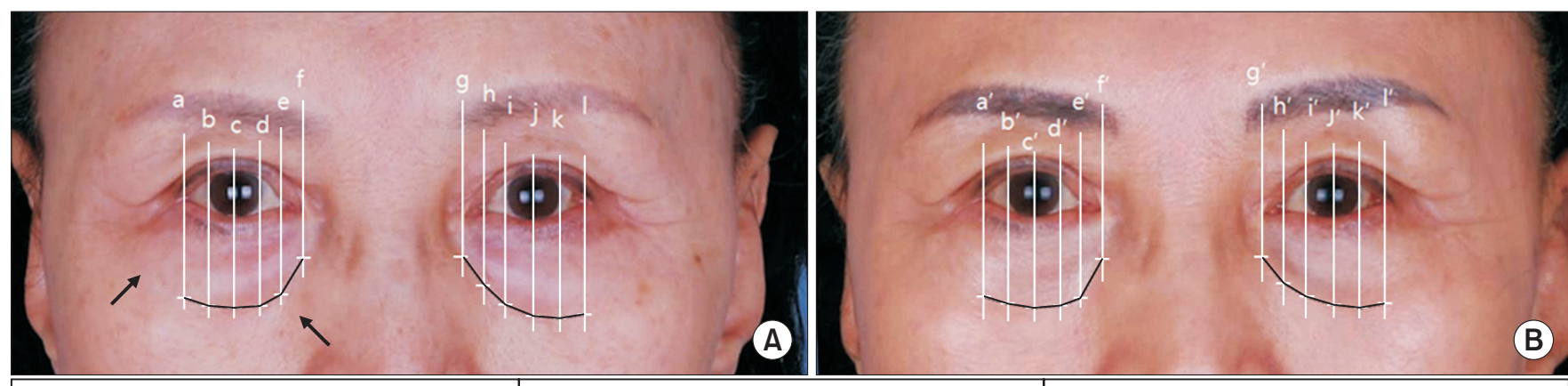

\begin{tabular}{|l|c|c|c|c|}
\hline \hline \multirow{2}{*}{} & \multicolumn{2}{|c|}{ Before $(\mathrm{A})$} & \multicolumn{2}{|c|}{ After (B) } \\
\cline { 2 - 5 } & Right & Left & 16.7 & Left \\
\hline Length of LCJ in the point of $\mathrm{c}$ and $\mathrm{j}(\mathrm{mm})$ & 17 & 17.7 & 16.5 & 171 \\
\hline bcd/ijk angle $\left(^{\circ}\right)$ & 155 & 164.5 & 16.5 \\
\hline
\end{tabular}
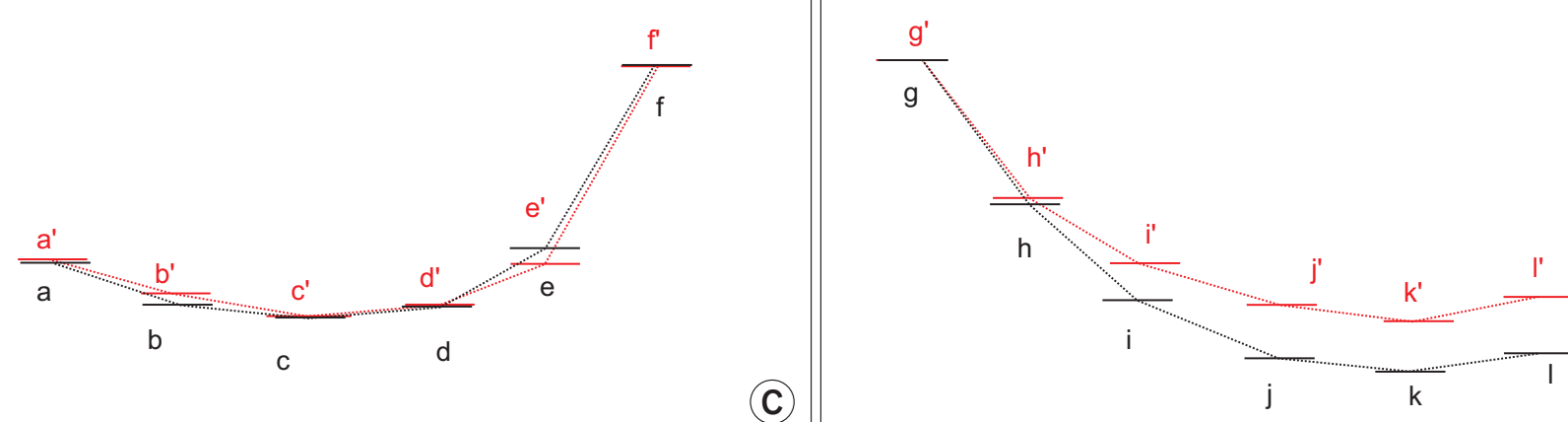

Fig. 3. A case of LCJ and bcd/ijk angle after revision TSILB including SOOF lifting and subperiosteal dissection over the malar eminence in a 69 -year-old female patient who had positive vector globe-to-skeletal rim relations (group 1 positive). (A) Before surgery, (B) 11 months after surgery, Change of LCJ at right (C)/left (D) eye (black dotted line means before TSILB, red dotted line means after TSILB). Line a-l and line a'l' indicate preoperative and postoperative LCJ, respectively. 2 black arrows indicate flat and depressive zygomatico-maxillary bone. LCJ, lidcheek junction; TSILB, traditional subciliary incision lower blepharoplasty; SOOF, suborbicularis oculi fat.

bination of medical fat removal and depression of the medial orbital rim.

Orbital fat protrusion, skin laxity, pretarsal depression, and lid laxity were significantly improved. Moreover, ectropion did not get worse than before the surgery despite skin removal to correct the lax skin. However, infraorbital hollowness seemed to have deepened and expanded.

\section{Group 1 negative}

The pre- and postoperative difference in the whole length of 


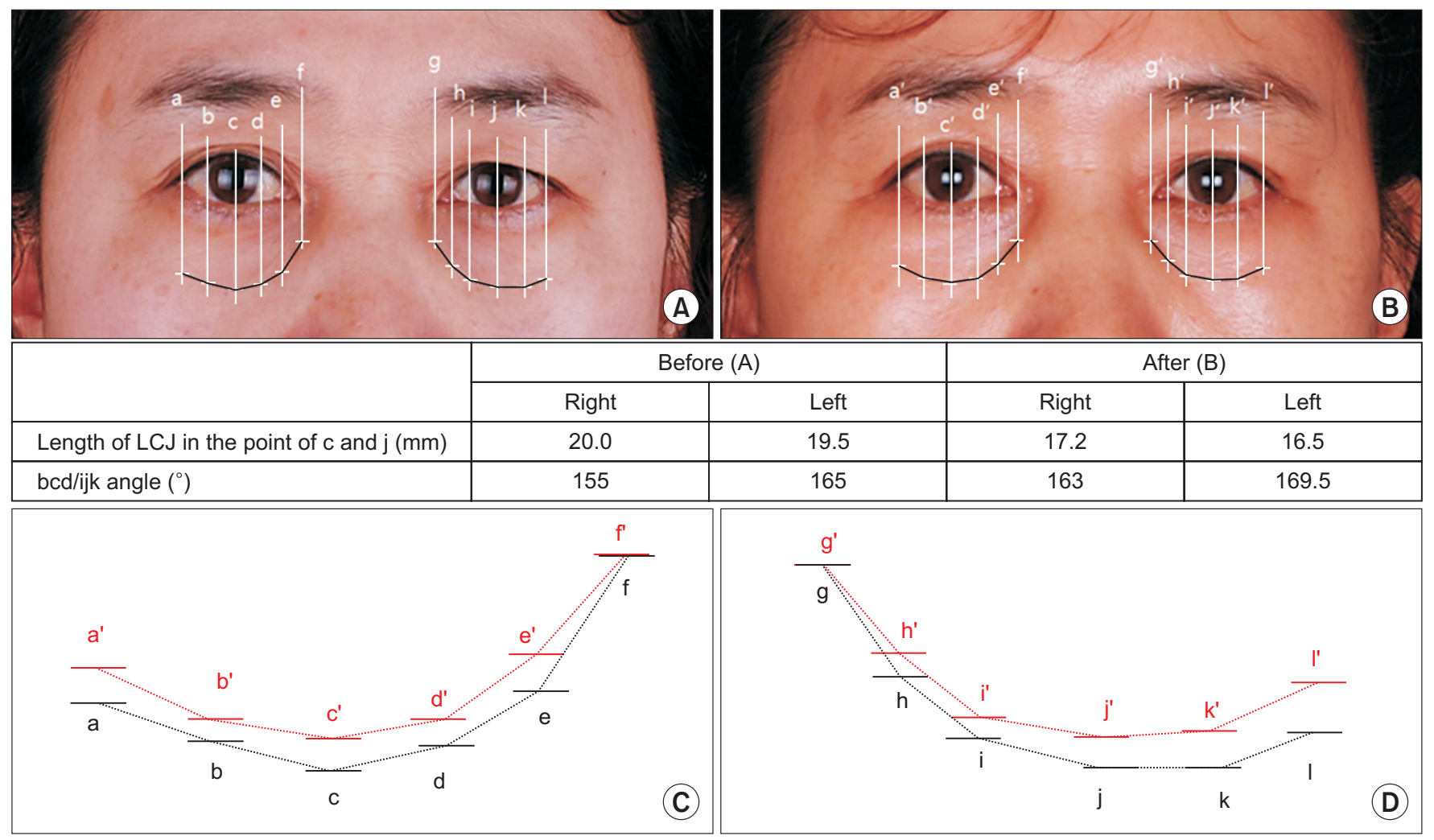

Fig. 4. A case of change of LCJ and bcd/ijk angle after TSILB including SOOF lifting and lateral retinacular canthopexy in a 52-year-old female patient who had negative vector globe-to-skeletal rim relations (group 1 negative). Additionally, subperiosteal dissection over right malar eminence was performed due to more prominent lid laxity in right lower lid. (A) Before surgery. (B) Seven months after surgery. Change of LCJ at right (C)/left (D) eye (black dotted line means before TSILB, red dotted line means after TSILB). Line a-l and line a'-l' indicate preoperative and postoperative LCJ, respectively. LCJ, lid-cheek junction; TSILB, traditional subciliary incision lower blepharoplasty; SOOF, suborbicularis oculi fat.

the LCJ seemed even. However, the change in the lateral area is greater than those in other areas (Fig. 4). The whole length of the LCJ was reduced due to the vertical and transverse shift of the LCJ by skin and muscle redraping. Both bcd and ijk angles were also increased, and it showed typical improvement of the aged lower lid.

Skin laxity with wrinkles was also improved, and pretarsal volume was considerably restored. In the right lower lid, malar eminence volume was increased, and lid laxity did not deteriorate. However, infraorbital hollowness was still seen (Fig. 4A, B). The infraorbital hollowness did not look more prominent than the case of Gln because of the negative vector of this patient.

\section{Group 2 positive}

Protruded orbital fat with lax skin was perfectly removed, and pretarsal volume was also significantly restored. Not only tear trough deformity was perfectly corrected, but mid-cheek furrow was also significantly improved (Fig. 5A, B).

The difference in pre-and postoperative length of the LCJ at middle and medial part of the eyelid was larger than that of the lateral part (Fig. 5C, D). Contour of the whole LCJ changed from V-shape to flat shape, and the length of the LCJ was mainly reduced in the middle and medial parts of the lid. The bcd/ijk angles were also remarkably increased. Vertical shifting of the LCJ looked prominent than transverse shifting. It was mainly caused by volume augmentation and not by skin and muscle redrapping.

\section{Group 2 negative}

The contour of the LCJ was dramatically changed from Vshape to flat shape, and the length of the LCJ was greatly reduced in the whole part of the lid (Fig. 6A, B). And the difference in pre-and postoperative length of the LCJ at the medial, middle, and lateral parts of the LCJ was even and great (Fig. 6C, D). Compared to G2p (Fig. 5), the lateral part of LCJ was much more shortened. It was caused by SOOF lifting and lateral canthopexy. The bcd/ijk angle was significantly increased due to the combination of volume augmentation and SOOF lifting 

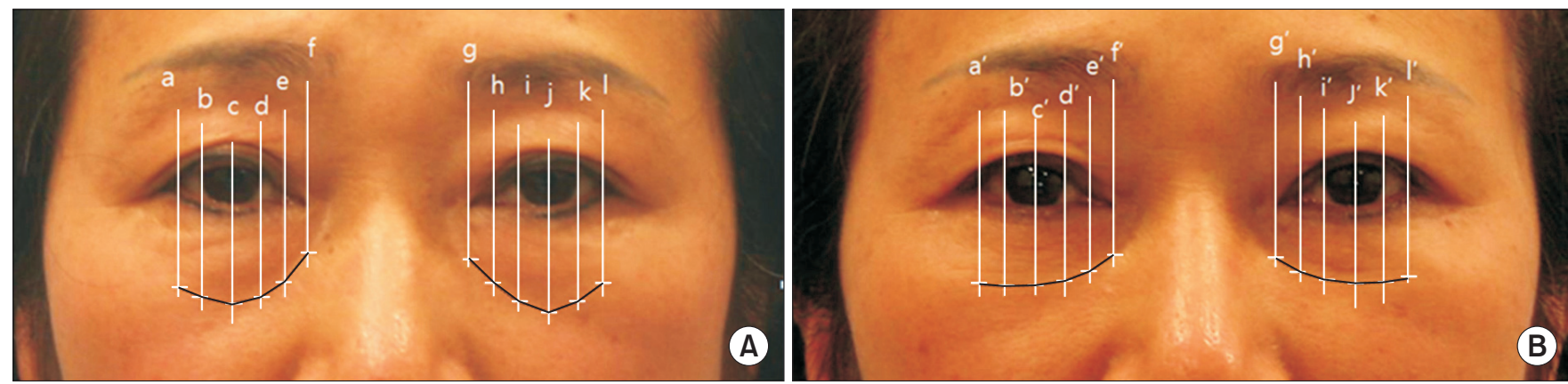

\begin{tabular}{|l|c|c|c|c|}
\hline \multirow{2}{*}{} & \multicolumn{2}{|c|}{ Before $(\mathrm{A})$} & \multicolumn{2}{|c|}{ After (B) } \\
\cline { 2 - 5 } & Right & Left & Right & 135 \\
\hline Length of LCJ in the point of $\mathrm{c}$ and $\mathrm{j}(\mathrm{mm})$ & 18.5 & 19.5 & 143.5 & 14 \\
\hline bcd/ijk angle $\left(^{\circ}\right)$ & 154 & 140 & 17.5 \\
\hline
\end{tabular}

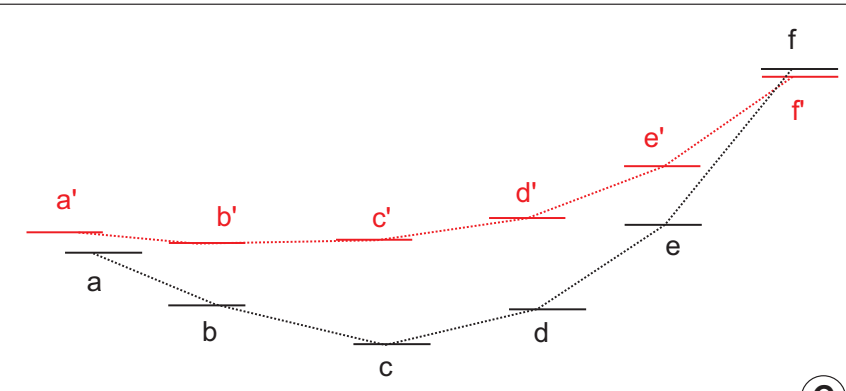

(C)

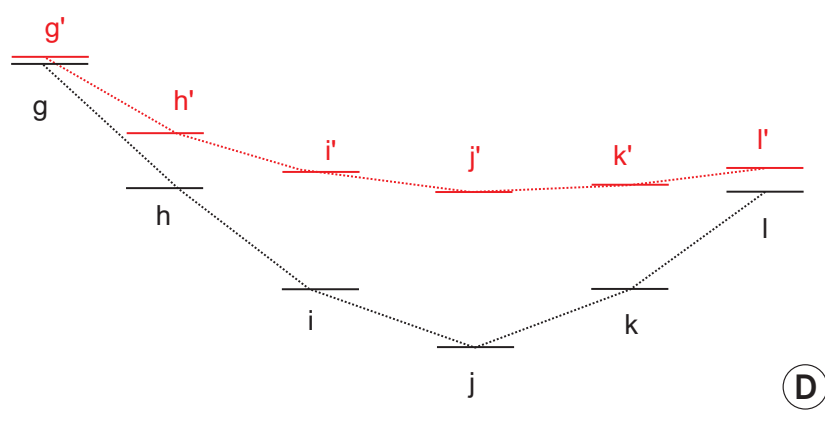

Fig. 5. A case of change of LCJ and bcd/ijk angle after combination of TSILB and fat grafting in a 50-year-old female patient who had positive vector globe-to-skeletal rim relations (group 2 positive). (A) Before surgery. (B) Six months after surgery. Change of LCJ at right (C)/left (D) eye (black dotted line means before TSILB, red dotted line means after TSILB). Line a-l and line $\mathrm{a}^{\prime}-\mathrm{l}^{\prime}$ indicate preoperative and postoperative LCJ, respectively. LCJ, lid-cheek junction; TSILB, traditional subciliary incision lower blepharoplasty; SOOF, suborbicularis oculi fat.

including soft tissue redrapping.

Protruded orbital fat with lax skin was perfectly removed, and pretarsal flatness was improved. However, preseptal volume deficiencies need to be improved for natural contour of the lower lid. Not only infraorbital hollowness was perfectly corrected, but the volume restoration of malar eminence and mid-cheek furrow were also greatly improved.

\section{Discussion}

TSILB is a commonly used surgical method to improve aged lower eyelids. Furthermore, fat grafting has been popularly used as a complementary procedure to rejuvenate it more perfectly. Generally, LCJ descends in aged persons or young persons with negative vector because the vertical length of the lower lid is increased by the laxity of the skin and muscle, protruded orbital fat, and resorption of bones [12]. However, after TSILB, the LCJ length was shortened, and its entire shape was shifted in the superolateral direction $[2,3]$. Hence, the authors evaluated the influence of complementary fat grafting on TSILB by observing the changes of LCJ.

In G1, after TSILB, the length of the LCJ was significantly decreased. However, there was no significant difference in the length of the LCJ between the subgroups (Table 2). It was because almost all negative vector patients and a few positive patients had undergone a combination of additional procedures such as SOOF lifting and lateral retinacular canthopexy.

In morphological analysis, the length of the identified points of the LCJ decreased overall. The bcd/ijk angles were also increased. These have resulted in typical improvement of aged lower lid by TSILB. Moreover, these results are consistent with the study reported by Kang et al. [3].

The length of the identified points of medial and middle part of the LCJ was mostly influenced by volume change due to orbital fat removal, the lateral part was influenced by redraping of skin and muscles. In Glp, middle and lateral points of the LCJ was shifted greater than the medial points, while, in G1n, the lateral points shifting looked more obvious than others. The 


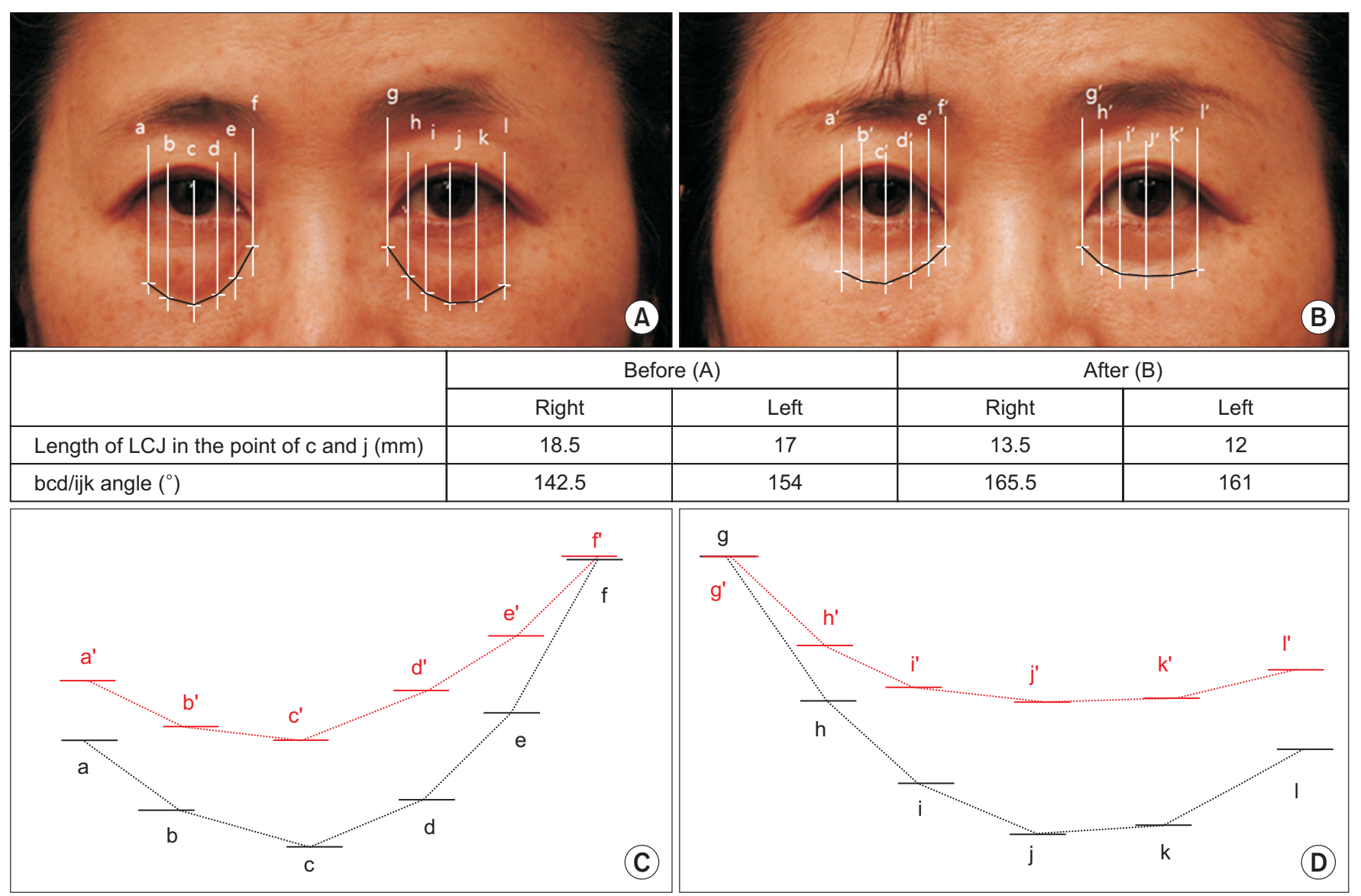

Fig. 6. A case of change of LCJ and bcd/ijk angle after combination of TSILB including SOOF lifting and lateral canthopexy and fat grafting in the 49-year-old female patient who had negative vector globe-to-skeletal rim relations (group 2 negative). (A) Before surgery. (B) Three months after surgery. Change of LCJ at right (C)/left (D) eye (black dotted line means before TSILB, red dotted line means after TSILB). Line a-l and line a'-l' indicate preoperative and postoperative LCJ, respectively. LCJ, lid-cheek junction; TSILB, traditional subciliary incision lower blepharoplasty; SOOF, suborbicularis oculi fat.

medial points of the LCJ were shifted much more in Glp. These results are consistent with the results of the study of Kang et al. [3] that the LCJ became longer instead in patients with negative vectors who underwent transconjunctival lower blepharoplasty alone.

However, the length of the LCJ did not improve much in the right eyelids of Glp patients (Fig. 3) than that of the left eyelids due to everted lower lid with lid laxity as a pre-existent complication. The point of "e" showed a decrease in LCJ length; it was caused by a small and flat maxillary bone, which can be distinguished from the preoperative photo and was also confirmed by physical examination. Nonetheless, the lids were greatly improved postoperatively by a combination of procedures of SOOF lifting and subperiosteal dissection without further complications. Anyhow, eventually, rejuvenation effect evaluated from the change in LCJ length greatly appeared in the left eyelids. The authors would like to suggest that rejuvenation effect of the right eyelids would be almost the same as the left eyelids if the partial deformity of zygomaticomaxillary bone was to be corrected by volume augmentation. This showed how important volume restoration surgery was.

In general, TSILB showed dramatic results for correction of wrinkles, skin laxity, and fat protrusion. However, infraorbital hollowness was slightly improved, or not improved at all, or sometimes got worse despite of a combination of SOOF lifting and lateral canthopexy.

In G2, according to the statistical analysis, together with typical rejuvenation effect, the length of the LCJ was greatly increased, and overall bcd/ijk angles were also remarkably increased. However, there were no significant differences in the pre- and postoperative lengths of the LCJ between the subgroups because the data were taken only from the middle point of the LCJ. Additionally, in the morphological analysis, the medial and middle points of the LCJ were greatly ascended than 
the lateral points in G2p, and entire points of the LCJ were remarkably ascended in G2n. These results mean that the medial and middle points of the LCJ were mainly affected by volume rebalancing procedures such as fat removal and grafting and not by a combination procedure such as SOOF lifting. However, the lateral points were mainly affected by redraping of skin and muscle.

The length of the LCJ in G2 decreased very significantly compared to that of G1. Moreover, pre- and postoperative difference was also great. Besides, the shape of the LCJ was changed from round with a middle V-point to shallow round with partially flat shape. These results showed a dramatic and fantastic rejuvenation appearance. It was certainly caused by the combination of both TSILB and complementary fat grafting.

In terms of statistics, the difference in the length of the LCJ between G2p and G2n was not significant, but the difference in the shape of the LCJ in the lateral points was prominent preand postoperatively. This was mainly due to the superolateral shifting of the soft tissues by a combination of SOOF lifting and lateral canthopexy.

In this paper, it is most important to describe why entire points of LCJ in G2 was much more shortened than those in Group 1.

To date, fat grafts with the purpose of combining with lower blepharoplasty have only been used for the purpose of volume augmentation to prevent shortcomings of traditional blepharoplasty such as infraorbital hollowing and incomplete blending of the LCJ [13]. Lupo et al. [14] reported that fat graft for cicatricial eyelid ectropion gave excellent outcomes, with release of the scar without recurrence. Fat was normally being grafted into submuscular, intramuscular, and subdermal layers to improve volume defect in the area after removal of filler. However, in this case, adipose-derived stem cells, which is the additional effect of fat graft, were also used for the purpose of potential and rapid improvement of the healing process and complete recovery of tissue integrity. However, in this study, the fat graft was performed by sequential autologous fat injection method, having the concept of volumetric face lifting $[9,10]$. The fat was grafted beneath the orbital retaining ligament and then just above the ligament in the palpebromalar grooves. Secondly, it was injected into the supraperiosteal layer and then the prezygomatic fat layer in the malar eminence. Moreover, in the tear trough deformity, it was grafted into the supraperiosteal layer (beneath the orbital retaining ligament) and then grafted into the SOOF layer as shown in Fig. 1B. When fat was grafted to mid-cheek furrow, it was injected into the supraperiosteal layer including the $\mathrm{zy}$ - gomaticobuccal ligament and then into the SOOF layer. Most of the grafted fat volume was injected into the supraperiosteal layer and deep fat layer. The subdermal and superficial fat grafting was performed only for skin tightening with a small volume. These approaches were obviously different from that of Lupo et al. [14]. Increased fat volume between the bone and orbital retaining ligament led to anterior projection of the zygomaticomaxillary bone and also lifted the ligament up, and that was why the LCJ was shortened. This result can be fully explained through the studies of Matros et al. [15] and Flowers [16] who reported that skeletal implants can create convex morphology by increasing projection and providing resuspension of sagged soft tissues by a concave bony platform.

With this mechanism, the additional fat graft, performed after the TSILB with orbital fat removal including orbital septum tightening and soft tissue redraping procedures, not only provided volume augmentation in the medial and middle points of the LCJ but also supported and lifted the soft tissues of the lower eyelids, resulting in a significant decrease in the length of the LCJ. Moreover, the infraorbital hollowness was perfectly improved by the combination of fat grafting. In addition, skin wrinkles, elasticity, and color tone were significantly improved due to the volume increase of the soft tissue of the lower eyelid itself.

It is beyond question that performing TSILB alone, although combined with SOOF lifting and lateral retinacular canthopexy, could not bring maximum results. Moreover, it is strongly recommended to perform an additional fat graft for perfect rejuvenation of aged lower eyelids.

Although TSILB with or without fat grafting showed significant rejuvenation effects, it is confirmed that complementary fat grafting not only prevented shortcomings of TSILB but also showed significant changes in LCJ length and shape as an ideal rejuvenation effect, which will promote the importance of volume balancing surgery in aged lower lid.

\section{Acknowledgments}

Our sincere gratitude to Minsu Park, PhD, who has contributed to the quality improvement of this paper with appropriate and excellent statistical analysis.

\section{Conflicts of interest}

The authors have nothing to disclose. 


\section{References}

1. Jacqueline MU, Kitaguchi Y, Takahashi Y, Kakizaki H. Agerelated eyelid changes. J Cosmet Med 2017;1:16-24.

2. Lambros V. Observations on periorbital and midface aging. Plast Reconstr Surg 2007;120:1367-76; discussion 1377.

3. Kang KJ, Yang HH, Chai CY. Assessment of rejuvenation by change of lid-cheek junction after transconjunctival and traditional subciliary incision blepharoplasty. J Cosmet Med 2017;1:30-8.

4. Mohadjer Y, Holds JB. Cosmetic lower eyelid blepharoplasty with fat repositioning via intra-SOOF dissection: surgical technique and initial outcomes. Ophthalmic Plast Reconstr Surg 2006;22:409-13.

5. Trepsat F. Periorbital rejuvenation combining fat grafting and blepharoplasties. Aesthetic Plast Surg 2003;27:243-53.

6. Morley AM, Malhotra R. Use of hyaluronic acid filler for teartrough rejuvenation as an alternative to lower eyelid surgery. Ophthalmic Plast Reconstr Surg 2011;27:69-73.

7. Coleman SR. Facial augmentation with structural fat grafting. Clin Plast Surg 2006;33:567-77.

8. Lam SM, Glasgold MJ, Glasgold RA. Complementary fat grafting. Philadelphia, PA: Lippincott, Williams \& Wilkins Co.; 2007. p. 58-77.

9. Kang KJ. SAFI (sequential autologous fat injection). Seoul:
Koonja Publishing Inc.; 2016. p. 71-6.

10. Kang KJ. SAFI (sequential autologous fat injection). Seoul: Koonja Publishing Inc.; 2016. p. 223-31.

11. Yaremchuk MJ. Restoring palpebral fissure shape after previous lower blepharoplasty. Plast Reconstr Surg 2003;111:44150; discussion 451-2.

12. Hester TR Jr, Codner MA, McCord CD, Nahai F, Giannopoulos A. Evolution of technique of the direct transblepharoplasty approach for the correction of lower lid and midfacial aging: maximizing results and minimizing complications in a 5-year experience. Plast Reconstr Surg 2000;105:393-406; discussion 407-8.

13. Tonnard PL, Verpaele AM, Zeltzer AA. Augmentation blepharoplasty: a review of 500 consecutive patients. Aesthet Surg J 2013;33:341-52.

14. Lupo F, Ioppolo L, Pino D, Meduri A, d'Alcontres FS, R Colonna $\mathrm{M}$, et al. Lipograft in cicatricial ectropion. Ann Ital Chir 2016;87:466-9.

15. Matros E, Momoh A, Yaremchuk MJ. The aging midfacial skeleton: implications for rejuvenation and reconstruction using implants. Facial Plast Surg 2009;25:252-9.

16. Flowers RS. Augmentation maxilloplasty. In: Terino EO, Flowers RS, editors. The art of alloplastic facial contouring. St. Louis: Mosby Co.; 2000. p. 129-50. 